\title{
Subspecialty certification in urology: a US perspective
}

\author{
Robert C Flanigan
}

Subspecialty certification of physicians is a 'hot' issue in the US and worldwide. Among urologists, it is an issue that evokes various emotions ranging from feelings that it would disrupt the 'family' of urology to arguments that it is necessary for the continued viability of our field.

The certification movement in the US began in 1917 with the birth of medical specialty boards that arose out of concerns for quality of care. Boards like the American Board of Urology (ABU), established in 1935, were designed as a way to address quality issues. The ABU is now one of 24 member boards of the American Board of Medical Specialties (ABMS). Currently the ABMS recognizes 37 general certificates and 94 subspecialty certificates, some of which are shared by two or more boards.

Given the relatively small size of our specialty some organizations, including the AUA and previously the $A B U$, have felt that it was unwise to "divide" urology by creating certificates of subspecialty qualification. One subspecialty group that questioned this belief and lobbied hard for subspecialty certification is pediatric urology. Pediatric urologists created fellowship programs recognized by the Accreditation Council for Graduate Medical Education and an in-service examination for their trainees. Last year, the ABU gave its formal support to this proposal and made application to the ABMS for subspecialty certification for pediatric urology. Two of the principles that the $A B U$ insisted upon were the absolute need for pediatric urology subspecialists to maintain their general urology boards at all times, and no designation of exclusivity for operative procedures that should only be done by pediatric urologists who held this subspecialty certificate.

What are the implications of this on efforts relating to future subspecialty certification in urology? Certainly, there are other
If urology is

to...ensure its

future in the

face of sub-

specialization, a feeling of cooperation and collaboration will need to be maintained between the subspecialties and the AUA and $A B U$.

RC Flanigan is the Albert J and Clair $R$ Speh Professor and Chairperson of Urology at Loyola University Medical Center, Loyola University Chicago, Maywood, IL, USA.

\section{Competing interests}

The author declared he has no competing interests

www.nature.com/clinicalpractice doi:10.1038/ncpuro0607 subspecialty groups within urology that want to move in this direction, including female pelvic medicine and reconstructive surgery, urologic oncology, and others. What are the implications of this movement for the average urologist? When pediatric urology achieves its subspecialty certification this year, most complex pediatric urology cases in the US will already be performed by pediatric urologists, and so the impact should be minimal. This is certainly not the case in any of the other previously mentioned areas of urology that might begin striving for the same status.

Why then should anyone in urology encourage this phenomenon? The groups interested in progressing towards this goal argue that it will help them fight off threats from other medical specialties. These groups also feel that efforts towards subspecialty certification should not be perceived as a threat to general urologists who perform surgery in a subspecialty area, but rather as a way to train a new breed of subspecialists who can embrace the threatened areas of their subspecialty, remain leaders in evolving areas, and become the trainers and teachers of future generations of urologists working in subspecialty areas.

I do not claim to have a crystal ball that can predict how this issue will play out, but I believe that subspecialty certification will be successfully accomplished by several urology subspecialties over the next decade. If urology is to avoid fragmentation and ensure its future in the face of subspecialization, a feeling of cooperation and collaboration will need to be maintained between the subspecialties and the AUA and ABU. To achieve this I believe that the $A B U$, and all of organized urology, must continue to insist that subspecialty certificate holders maintain their general $A B U$ certificate and that the subspecialty organizations continue to hold their principal academic meeting in conjunction with the AUA annual meeting. 